\title{
Induction of labour at 37 weeks for suspected fetal macrosomia may reduce birth trauma
}

Kate F. Walker, PhD, MRCOG

Jim G. Thornton, MD, FRCOG

Division of Child Health, Obstetrics and Gynaecology, School of Medicine, University of Nottingham, or at jim.thornton@nottingham.ac.uk.

Dr Thornton reports personal fees and non-financial support from Ferring Pharmaceuticals.

Dr Walker has no conflicts of interest to declare.

\section{Context}

Mothers with big babies tend to have longer labours and more difficult births. They may require caesarean section, or instrumental vaginal delivery. They may also sustain perineal injury or more seriously the head may deliver and the shoulders get stuck, so called shoulder dystocia. This severe complication may cause birth injury, including brachial plexus injury (2-16\%) which may be permanent and disabling. Finally the baby may suffer bony fractures or birth asphyxia with risk of neurological damage or death. Obstetricians have wondered whether inducing labour early might make birth easier and reduce injury, but have been cautious to implement this policy due to concerns that induced labour may be longer or increase caesareans, and because the diagnosis of macrosomia, even using ultrasound scan is notoriously inaccurate.

Methods

This is a systematic review of randomised controlled trials of induction of labour at term for suspected fetal macrosomia. Suspected fetal macrosomia was defined as an ultrasonic estimated fetal weight $>4000 \mathrm{~g}$ or $\geq 95^{\text {th }}$ centile. The primary outcome was caesarean delivery. RCTs looking exclusively at a population of women with pre-existing or gestational diabetes were excluded, but RCTs with some women with those conditions were included.

Findings

There was no significant effect on Caesarean delivery [relative risk (RR) $0.91,95 \%$ confidence interval (CI), 0.76-1.09], operative delivery, shoulder dystocia, intracranial haemorrhage, brachial plexus palsy, low Apgar score, cord blood $\mathrm{pH}<7$, or mean birth weight. The lack of effect on Caesarean section accords with other randomised trial of induction near term $(1,2)$.

The main benefit from induction was reduced fetal fractures (RR $0.17,95 \% \mathrm{Cl} 0.03-0.79$ ). There were some harms from induction, hyperbilirubinemia (8.8\% versus $2.9 \%$; $R R 3.03,95 \% \mathrm{Cl} 1.60-5.74$ ) and phototherapy (11.0\% versus 6.6\%; RR $1.68,95 \% \mathrm{Cl} 1.07-2.66)$.

\section{Commentary}

This systematic review from BJOG is timely because in 2015 a large randomised trial, (DAME) (3) of 822 participants was published but was too small to draw firm conclusions. This systematic review 
includes the same trials, and draws similar conclusion to the updated Cochrane review on the same topic (4). The Cochrane review calculates the number needed to treat (NNT) to prevent one fracture as 60 .

Although Magro-Malosso do not comment on it, there appeared to also be an adverse effect of perineal injury. In the largest study, third- and fourth-degree perineal tears were increased in the induction group ( $\mathrm{RR} 3.70,95 \% \mathrm{Cl} 1.04$ - 13.17). There is also a concern from observational studies that induction at early term gestations (37-38 weeks) may increase the risk of longer term developmental harm $(5,6)$. Emerging evidence shows that gestational age may be best conceptualised as a continuum in which the risk of adverse neurodevelopmental outcomes increases with each decreasing week of gestation at birth, from 40 weeks gestation. Thus induction even as late as 39 weeks may have previously unforeseen impact on development.

Implications for practice

Unsurprisingly reviewers' interpretation of these data vary. Magro-Malosso concluded "induction of labour $\geq 38$ weeks for suspected fetal macrosomia is associated with a significant decrease in fetal fractures, and therefore can be considered as a reasonable option."

The Cochrane review was more cautious concluding "although some parents and doctors may feel the evidence already justifies induction, others may justifiably disagree. Further trials of induction shortly before term for suspected fetal macrosomia are needed. Such trials should concentrate on refining the optimum gestation of induction, and improving the accuracy of the diagnosis of macrosomia."

\section{References}

1. Walker KF, Bugg GJ, Macpherson M, McCormick C, Grace N, Wildsmith C, et al. Randomized Trial of Labor Induction in Women 35 Years of Age or Older. N Engl J Med. 2016 Mar;374(9):813-22. PubMed PMID: 26962902. eng.

2. Wood S, Cooper S, Ross S. Does induction of labour increase the risk of caesarean section? A systematic review and meta-analysis of trials in women with intact membranes. BJOG : an international journal of obstetrics and gynaecology. 2014 May;121(6):674-85; discussion 85. PubMed PMID: 23834460.

3. Boulvain M, Senat MV, Perrotin F, Winer N, Beucher G, Subtil D, et al. Induction of labour versus expectant management for large-for-date fetuses: a randomised controlled trial. Lancet. 2015 Jun;385(9987):2600-5. PubMed PMID: 25863654. eng.

4. Boulvain M, Irion O, Dowswell T, Thornton JG. Induction of labour at or near term for suspected fetal macrosomia. Cochrane Database Syst Rev. 2016 (5):CD000938. PubMed PMID: 27208913. eng.

5. Noble KG, Fifer WP, Rauh VA, Nomura Y, Andrews HF. Academic Achievement Varies With Gestational Age Among Children Born at Term. Pediatrics. 2012 Aug;130(2):E257-E64. PubMed PMID: WOS:000307123000002. English.

6. Rose O, Blanco E, Martinez SM, Sim EK, Castillo M, Lozoff B, et al. Developmental Scores at 1 Year With Increasing Gestational Age, 37-41 Weeks. Pediatrics. 2013 May;131(5):E1475-E81. PubMed PMID: WOS:000318270700012. English. 